\title{
Pengembangan Aplikasi Instrumen Gamelan Gong Kebyar Berbasis Android
}

\author{
I Putu Surya Pratama Wardhana ${ }^{1}$, I Gede Mahendra Darmawiguna ${ }^{2}$, \\ I Made Gede Sunarya ${ }^{3}$ \\ Jurusan Pendidikan Teknik Informatika \\ Universitas Pendidikan Ganesha \\ Singaraja, Bali \\ E-mail: rapid.distorsy@gmail.com ${ }^{1}$, igd.mahendra.d@gmail.com ${ }^{2}$, imadegedesunarya@gmail.com ${ }^{3}$
}

\begin{abstract}
Abstrak-Gong Kebyar adalah salah satu dari barungan gamelan Bali berlaras "pelog lima nada" yang dalam teknik permainannya memakai sistem kebyar. Aplikasi instrumen gamelan Gong Kebyar merupakan perangkat lunak yang mensimulasikan instrumen Gong Kebyar agar bisa dioperasikan pada sistem operasi Android. Penelitian ini bertujuan untuk merancang dan mengimplementasikan rancangan aplikasi instrumen gamelan Gong Kebyar berbasis Android.

Aplikasi instrumen gamelan Gong Kebyar berbasis Android dikembangkan dengan menggunakan siklus hidup pengembangan perangkat lunak dalam bentuk sekuensial linier atau model air terjun (Waterfall). Fitur utama dari aplikasi ini adalah memainkan instrumen gamelan Gong Kebyar, selain itu terdapat fitur video agar pengguna mengetahui cara memainkan instrumen yang sebenarnya/nyata. Perancangan dilakukan dengan menggunakan model fungsional berupa UML (Unified Modeling Languange) dan diimplementasikan dalam bahasa pemrograman Java dengan menggunakan editor Eclipse, plug-ins ADT (Android Development Tools) dan AndEngine sebagai library tambahan.

Hasil dari penelitian ini yaitu berupa aplikasi instrumen gamelan Gong Kebyar berbasis Android yang telah berhasil dikembangkan. Seluruh kebutuhan fungsional telah berhasil diimplementasikan sesuai dengan rancangan.
\end{abstract}

Kata kunci - Instrumen, Gong Kebyar, Android Abstract-Gong Kebyar is one of barungan Bali's "pelog lima nada"-harmonized gamelan groups which the playing technique uses kebyar system. The gamelan Gong Kebyar instruments of application is software that simulates the Gong Kebyar instruments so that it can be operated on the Android operating system. This research aims to design and implement a draft application of gamelan Gong instruments Android-based.

The gamelan Gong Kebyar instruments of applications Android-based is developed by using the software development life cycle in the form of a linear or sequential waterfall model. The main features of this application are to play the gamelan Gong Kebyar instruments, additionally there are video features so that users know how to play the actual/real instruments. The application is design by using a functional model of a UML (Unified Modeling Languange) and implemented by the Java programming language using Eclipse as editor, plugins ADT (Android Development Tools) and AndEngine as additional libraries.

The results of this research, is gamelan Gong Kebyar instruments of applications based on Android that has been successfully developed. The entire functional requirements have been successfully implemented in accordance with the draft.

Keyword - Instrument, Gong Kebyar, Android

\section{PENDAHULUAN}

Indonesia adalah sebuah negara yang kaya akan keunikan suku dan budaya. Tiap-tiap daerah di Indonesia memiliki ciri khas kebudayaan berbeda satu sama lain. Kebudayaan berarti keseluruhan gagasan dan karya manusia yang harus dibiasakan dengan belajar serta keseluruhan dari hasil budi pekertinya [1].

Bicara mengenai budaya tidak akan terlepas dari kesenian, karena dari budayalah yang menumbuhkan kesenian yang beraneka ragam. Pulau Bali adalah salah satu provinsi di Indonesia dan telah terkenal ke seluruh pelosok dunia. Hal ini tidak hanya disebabkan oleh faktor keindahan alamnya, tapi lebih dari itu Bali banyak menarik perhatian dunia karena seni budayanya. Seni memiliki berbagai bidang, diantaranya seni pahat, seni gamelan, seni lukis, seni tari, seni hias, seni patung dan lain-lain. Gamelan merupakan salah satu alat musik tradisional Bali [2].

Seiring perjalanan waktu, gamelan Bali pun ikut mengalami perkembangan. Gong Kebyar 
adalah salah satu tanda munculnya pegaruh zaman terhadap kesenian di Bali. Gong Kebyar merupakan perkembangan dari Gong Gede yang beberapa instrumennya dihilangkan. Secara definisi Gong kebyar adalah salah satu barungan gamelan Bali berlaras pelog lima nada yang melahirkan ungkapan musikal benuansa kebyar. Sebagai gamelan yang berfungsi menyajikan gending-gending pategak (instrumental), mengiringi berbagai jenis tarian maupun dimanfaatkan sebagai media pembelajaran [3].

Di era globalisasi sekarang dengan berbagai macam transfer kebudayaan luar yang mudah masuk, mengakibatkan generasi muda bisa lupa akan kebudayaannya sendiri. Bagi Indonesia, merasuknya nilai-nilai Barat yang menumpang arus globalisasi ke kalangan masyarakat Indonesia merupakan ancaman bagi budaya asli yang mencitrakan lokalitas khas daerah-daerah di negeri ini. Kesenian-kesenian daerah seperti ludruk, ketoprak, wayang, gamelan, dan tari menghadapi ancaman serius dari berkembangnya budaya pop khas Barat yang semakin diminati masyarakat karena dianggap lebih modern [4]. Padahal salah satu dari 17 jenis instrumen kebudayaan dalam bentuk seni gamelan yang banyak diminati oleh masyarakat dari luar negeri adalah Gong Kebyar [5]. Dengan adanya arus globalisasi yang berjalan dengan cepat menjadi ancaman bagi eksistensi budaya lokal di daerahnya sendiri. Budaya lokal yang seharusnya menjadi identitas kebudayaan Indonesia yang beragam, bisa saja memudar ditelan waktu.

Solusi yang peneliti usulkan adalah dengan mengembangkan sebuah aplikasi instrumen gamelan Gong Kebyar yang dikembangkan pada sistem operasi Android. Aplikasi dikembangkan pada sistem operasi Android karena Android banyak digunakan oleh masyarakat dan memiliki beberapa kelebihan seperti harga terbilang terjangkau, mampu digunakan di berbagai segmen, mulai dari kalangan menengah, bawah, maupun eksekutif muda dan fiturnya yang lengkap selalu update [6]. Dengan dikembangkannya aplikasi ini, diharapkan akan dapat menjaga keajegan dan kelestarian instrumen gamelan tradisional khususnya Gong Kebyar, mengingat harga satu barungan Gong Kebyar lengkap cukup mahal, yakni mencapai lebih dari dua ratus juta rupiah.

\section{KAJIAN TEORI}

A. Gong Kebyar
Gong Kebyar adalah salah satu dari barungan gamelan Bali yang menyajikan "tabuhtabuh kekebyaran", yaitu suatu bentuk komposisi yang dihasilkan dengan memainkan seluruh alat gamelan secara serentak dalam aksentuasi yang poliritmik, dinamis dan harmonis. Dengan demikian yang dinamakan Gong Kebyar adalah barungan gamelan Bali yang berlaras "pelog lima nada" yang dalam teknik permainannya memakai sistem kebyar [3].

\section{B. Android}

Android adalah sistem operasi bergerak (mobile operating system) yang mengadopsi sistem operasi Linux, namun telah dimodifikasi. Keuntungan utama dari Android adalah adanya pendekatan aplikasi secara terpadu. Pengembang hanya berkonsentrasi pada aplikasinya saja, aplikasi tersebut bisa berjalan pada beberapa perangkat yang berbeda selama masih ditenagai oleh Android (pengembang tidak perlu mempertimbangkan kebutuhan jenis perangkatnya) [7].

\section{Eclipse}

Eclipse adalah IDE (Integrated Development Environment) software yang digunakan oleh banyak bahasa pemrograman seperti Java, Ada, C, C++, COBOL, Phyton dan lain-lain. Di dalam IDE Elipse terdapat layanan sistem extensible (semacam sistem penambahan plugins), editor, debugger, control tools, pengaturan direktori dan lain-lain. IDE Eclipse intinya adalah suatu software yang lingkungannya dikordinasikan agar memudahkan pengembang membangun suatu aplikasi [7].

\section{AndEngine}

AndEngine merupakan game engine yang memfokuskan pada pembuatan game berbasis 2D di platform Android. Karena sudah berupa engine maka pembuat game akan dipermudah dengan disediakan banyak fitur-fitur untuk membuat game. Berikut beberapa fitur yang disediakan oleh AndEngine seperti resolusi, landscape/potrait, sprite, animasi, pengecekan tubrukan (collision) texture, font, event touch dan accelerometer, particle dan lain-lain [8].

\section{METODOLOGI}

\section{A. Analisis Masalah dan Usulan Solusi}

Berdasarkan analisis yang peneliti lakukan, terdapat permasalahan yang terjadi di masyarakat 
yaitu adanyanya transfer kebudayaan luar yang mudah masuk, mengakibatkan generasi muda bisa lupa akan kebudayaannya sendiri [4]. Padahal kebudayaan dalam bentuk seni gamelan banyak diminati oleh masyarakat dari luar negeri. Sekitar 17 jenis instrumen musik tradisional Bali (gamelan) berkembang di mancanegara, bahkan mampu sejajar dengan seni musik barat, salah satunya adalah Gong Kebyar [5].

Solusi yang peneliti usulkan yaitu dengan mengembangkan sebuah aplikasi Instrumen Gamelan Gong Kebyar yang dikembangkan pada sistem operasi Android. Aplikasi dikembangkan pada sistem operasi Android, karena Android banyak digunakan oleh masyarakat dan memiliki beberapa kelebihan seperti harga terbilang terjangkau, mampu digunakan di berbagai segmen, mulai dari kalangan menengah, bawah, maupun eksekutif muda dan fiturnya yang lengkap selalu update [6]. Dengan dikembangkannya aplikasi ini, diharapkan seluruh masyarakat mampu belajar memainkan instrumen Gong Kebyar serta menjaga keajegannya dan kelestarian seni gamelan di Bali.

B. Analisis Perangkat Lunak

1. Kebutuhan Perangkat Lunak

Aplikasi instrumen gamelan gong kebyar berbasis Android dirancang agar dapat mengimplementasikan kebutuhan fungsional sebagai berikut.

a. Menampilkan antarmuka menu utama yang terdiri dari menu "Start", "Record List", "About", dan "Exit".

b. Menampilkan antarmuka daftar instrumen gamelan Gong Kebyar yang disediakan saat menekan "Start".

c. Merekam suara instrumen.

d. Mengunduh video.

e. Memutar video.

f. Menampilkan tutorial permainan.

g. Menampilkan daftar rekaman (Record List).

h. Menampilkan informasi tentang pengembang aplikasi.

i. Menampilkan pilihan konfirmasi saat keluar aplikasi.

Adapun kebutuhan non-fungsional dari aplikasi yang dikembangkan yaitu aplikasi dibuat agar user friendly bagi pengguna sehingga pengguna mudah untuk menggunakan aplikasi.

2. Tujuan Pengembangan Perangkat Lunak

Adapun tujuan pengembangan perangkat lunak adalah sebagai berikut. a. Aplikasi dapat menampilkan antarmuka menu utama yang terdiri dari "Start", "Record List", "About", dan "Exit".

b. Aplikasi dapat menampilkan antarmuka daftar instrumen gamelan Gong Kebyar yang disediakan saat menekan "Start".

c. Aplikasi dapat merekam suara instrumen.

d. Aplikasi dapat mengunduh video.

e. Aplikasi dapat memutar video.

f. Aplikasi dapat menampilkan tutorial permainan.

g. Aplikasi dapat menampilkan daftar rekaman (record list).

h. Aplikasi dapat menampilkan informasi tentang pengembang aplikasi.

i. Aplikasi dapat menampilkan pilihan konfirmasi saat keluar aplikasi.

3. Masukan dan Keluaran Perangkat Lunak

Aplikasi instrumen gamelan Gong Kebyar berbasis Android menerima input berupa sentuhan (touch) pada layar dan suara, sedangkan keluaran (output) berupa suara.

\section{Model Fungsional Perangkat Lunak}

Dalam pengembangan aplikasi ini, peneliti menggunakan tiga macam diagram yaitu use-case diagram, activity diagram, dan sequence diagram. a. Use Case Diagram

Sebuah use case merepresentasikan sebuah interaksi antara aktor dengan sistem. Seorang/sebuah aktor adalah sebuah entitas manusia atau mesin yang berinteraksi dengan sistem untuk melakukan pekerjaan-pekerjaan tertentu [9]. Gambar 1 merupakan use case diagram aplikasi ini.

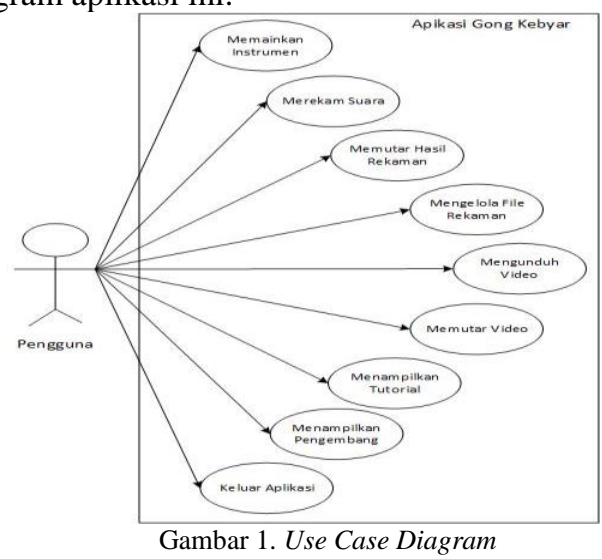

\section{b. Activity Diagram}

Activity diagram menggambarkan berbagai alir aktivitas dalam sistem yang sedang dirancang, bagaimana masing-masing alir berawal, decision 
yang mungkin terjadi, dan bagaimana mereka berakhir [9]. Gambar 2 adalah activity diagram memainkan instrumen.

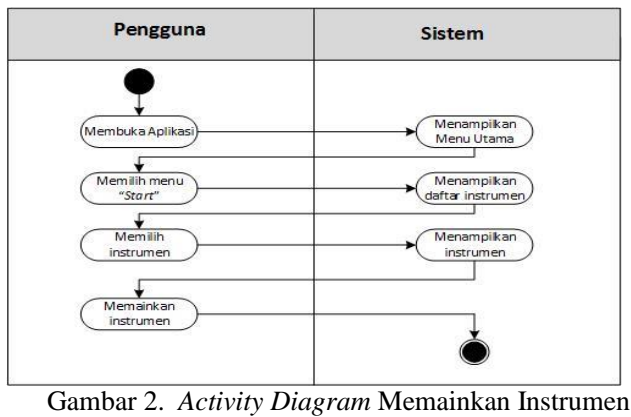

\section{c. Sequence Diagram}

Sequence diagram menggambarkan interaksi antar objek di dalam dan di sekitar sistem (termasuk pengguna, display, dan sebagainya) berupa message yang digambarkan terhadap waktu. Sequence diagram terdiri atar dimensi vertikal (waktu) dan dimensi horizontal (objekobjek yang terkait) [9]. Sequence diagram memainkan instrumen dapat dilihat pada Gambar 3.

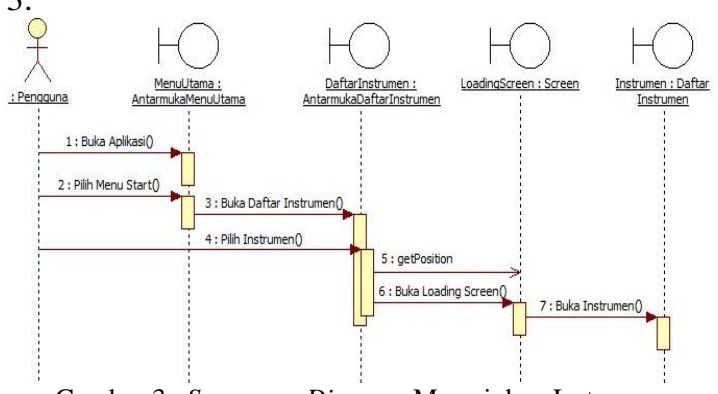

Gambar 3. Sequence Diagram Memainkan Instrumen

C. Perancangan Perangkat Lunak

1. Batasan Perancangan Perangkat Lunak

Batasan masalah pada penelitian ini yaitu jumlah instrumen gamelan Gong Kebyar yang dapat dimainkan dalam aplikasi bersifat statis, artinya pengguna tidak dapat menambahkan instrumen baru ke dalam aplikasi, serta alamat unduh video pada aplikasi tidak bisa diubah.

\section{Perancangan Struktur Menu}

Perancangan struktur menu menampilkan berbagai menu yang tersedia pada aplikasi. Menumenu yang ada pada aplikasi digambarkan dalam bentuk hirarki. Tiap-tiap menu terhubung melalui garis yang menyatakan adanya hubungan dari satu menu ke menu yang lainnya.

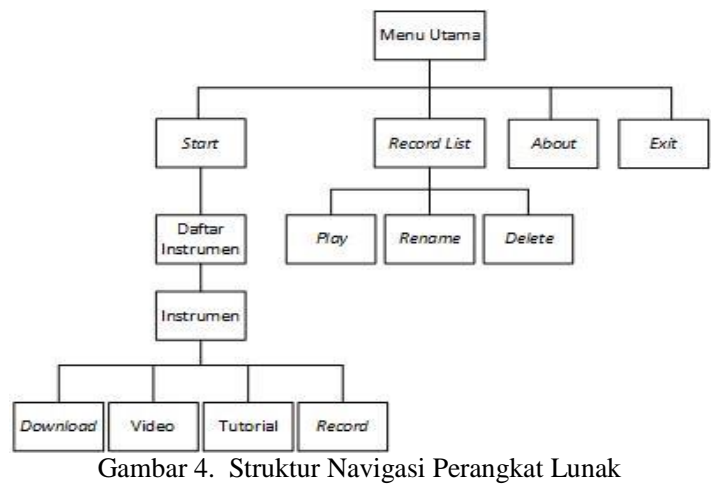

3. Perancangan Antarmuka Perangkat Lunak

Perancangan antarmuka perangkat lunak merupakan proses pembuatan antarmuka yang akan digunakan untuk berinteraksi antara pengguna dengan perangkat lunak. Rancangan antarmuka yang dibuat sebaik mungkin sehingga aplikasi yang dikembangkan bersifat user friendly. Beberapa perancangan antarmuka aplikasi ini bisa dilihat pada Gambar 5 sampai Gambar 13.

a. Perancangan Antarmuka Menu Utama Menu utama terdiri dari menu "Start", "Record List", "About", dan "Exit" bisa dilihat pada Gambar 5.

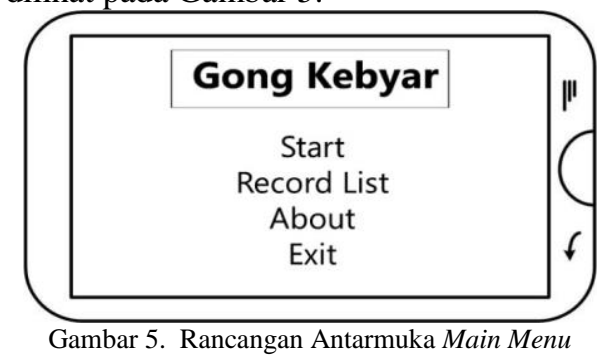

b. Perancangan Antarmuka Daftar Instrumen Antarmuka daftar instrumen menyediakan 18 instrumen gamelan Gong Kebyar untuk dimainkan ada pada Gambar 6.

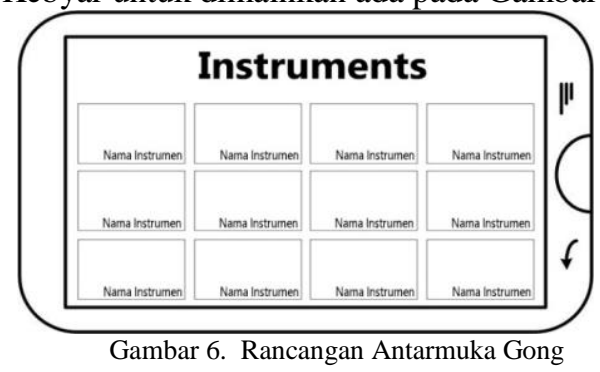

c. Perancangan Antarmuka Instrumen

Pada antarmuka ini terdapat lima tombol di atas instrumen yang terdiri buka rekaman, putar rekaman, ulangi rekaman, dan mulai / hentikan rekaman. 
Cara memainkan intrumen yaitu menyentuh bagian yang terdapat pada instrumen.

Gambar 7 sampai Gambar 10 merupakan beberapa rancangan antarmuka instrumen yang ada pada aplikasi instrumen gamelan Gong Kebyar berbasis Android.

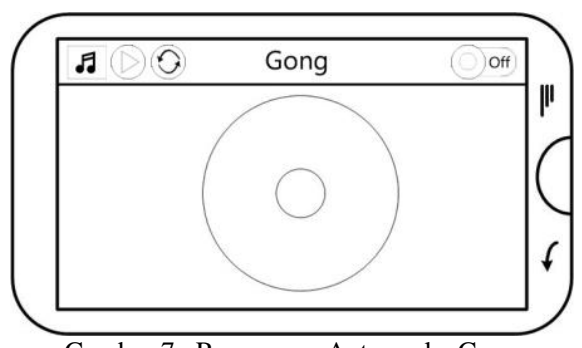

Gambar 7. Rancangan Antarmuka Gong

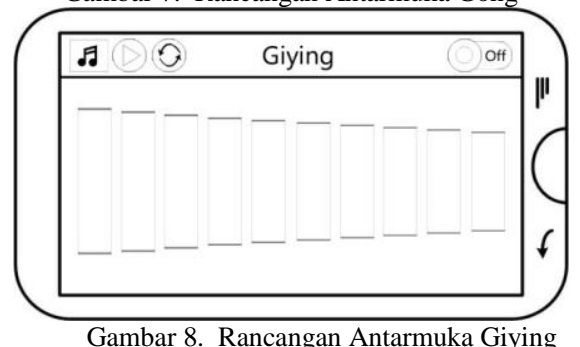

Gambar 8. Rancangan Antarmuka Giying

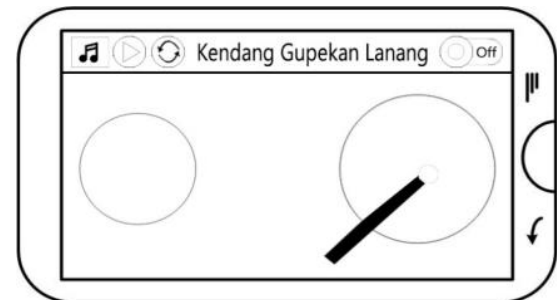

Gambar 9. Rancangan Antarmuka Kendang Gupekan Lanang

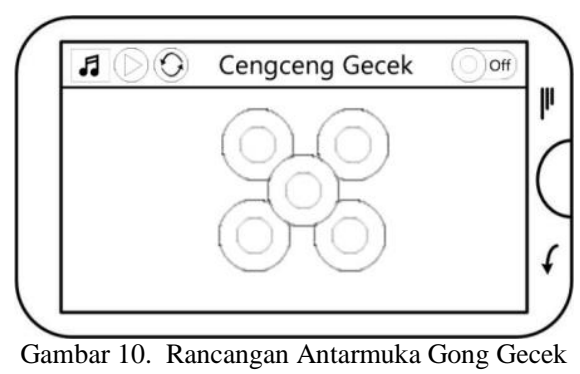

d. Perancangan Antarmuka Download

Gambar 11 menampilkan daftar 18 video instrumen yang bisa diunduh.

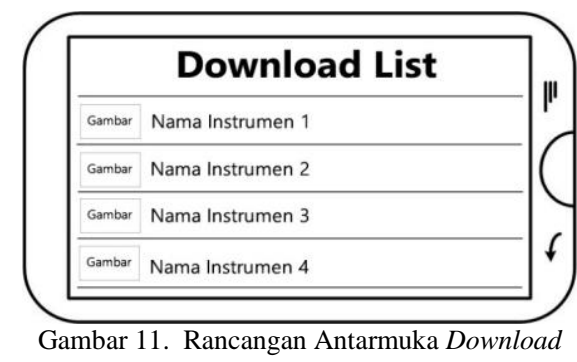

e. Perancangan Antarmuka Video

Gambar 12 merupakan antarmuka video yang akan diputar sesuai dengan instrumen yang dipilih pada antarmuka daftar instrumen.

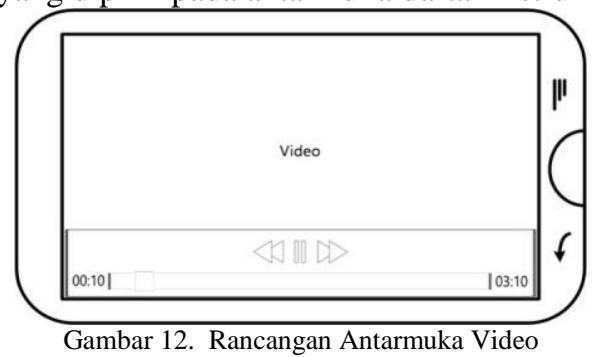

f. Perancangan Antarmuka Daftar Rekaman

Gambar 13 merupakan antarmuka daftar rekaman. Seluruh hasil rekaman yang direkam aplikasi akan ditampilkan dalam bentuk daftar.

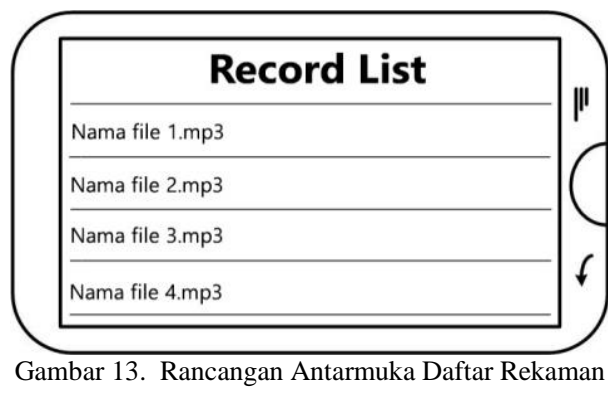

\section{IV.PEMBAHASAN}

A. Implementasi Perangkat Lunak

1. Lingkungan Implementasi Perangkat Lunak Implementasi Aplikasi Instrumen Gamelan Gong Kebyar berbasis Android dilakukan pada lingkungan perangkat lunak yaitu:

a. Eclipse Version: 4.2.1

b. Plugins ADT (Android Development Tools) Version: 22.3.0-887826

c. AVD (Android Virtual Device)

d. AndEngine GLES2

e. Adobe Photoshop CS 6

f. WavePad Sound Editor Masters Edition v 5.33 
Adapun lingkungan perangkat kerasnya yaitu sebuah laptop dengan spesifikasi sebagai berikut.

a. Monitor 14,1 inchi

b. Memori 4 GB RAM

c. Harddisk $500 \mathrm{~GB}$

d. Processor Intel ${ }^{\circledR}$ Core $^{\mathrm{TM}}$ i3 2.4 Ghz.

e. VGA nVidia GT410M 1GB

Perangkat keras lainnya yaitu sebuah perangkat Android dengan spesifikasi sebagai berikut.

a. Layar 4,3 inch dengan resolusi layar $480 \mathrm{x}$ 854 pixels

b. RAM 1 GByte

c. CPU $1 \mathrm{GHz}$ Dual Core Krait processor

d. GPU Adreno 305

e. Touchscreen multi touch

2. Batasan Implementasi Perangkat Lunak

a. Spesifikasi perangkat minimal yang diperlukan untuk menjalankan aplikasi yaitu Processor ARM-v7a, GPU kelas mid-end, RAM 256 MB, OS Android versi 2.3 (Gingerbread), dan resolusi layar 320 x 480 . Sedangkan spesifikasi yang direkomendasikan yaitu Processor Dual Core ARM-v7a, GPU kelas mid-end, RAM 512 MB, OS Android versi 4.0 (Ice Cream Sandwich), dan resolusi layar 600 x 1024.

b. Suara dan musik yang dari aplikasi akan berbeda antara menggunakan speaker perangkat Android dengan menggunakan speaker atau earphone tambahan

c. Instrumen Jegogan, Kempur, dan Gong perlu menggunakan speaker atau earphones tambahan agar menghasilkan suara yang baik.

d. Suara dan musik yang dihasilkan oleh aplikasi akan semakin baik jika menggunakan speaker atau earphones tambahan.

e. Fitur merekam suara yang disediakan aplikasi akan menghasilkan rekaman yang baik jika mic pada perangkat android menangkap suara dengan jelas dari suara yang dihasilkan instrumen pada aplikasi.

3. Implementasi Antarmuka Perangkat Lunak Implementasi antarmuka dilakukan sesuai dengan rancangan antarmuka yang telah dibuat sebelumnya.

a. Implementasi Antarmuka Menu Utama

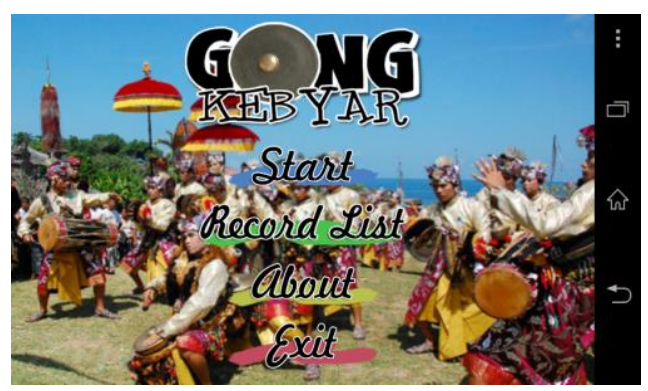

Gambar 14. Rancangan Antarmuka Daftar Rekaman

b. Implementasi Antarmuka Daftar Instrumen

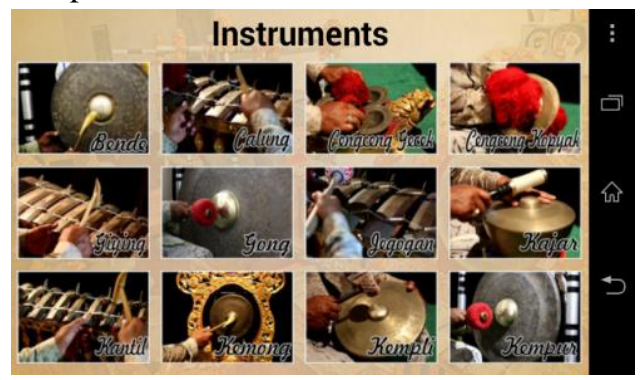

Gambar 15. Rancangan Antarmuka Daftar Rekaman

c. Implementasi Antarmuka Instrumen Gong Wadon

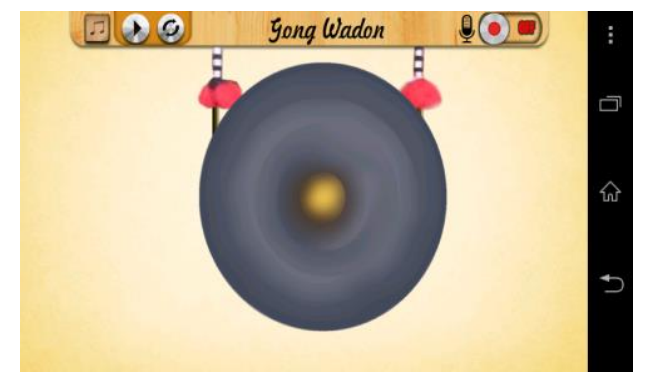

Gambar 16. Rancangan Antarmuka Instrumen Gong Wadon

d. Implementasi Antarmuka Instrumen Giying

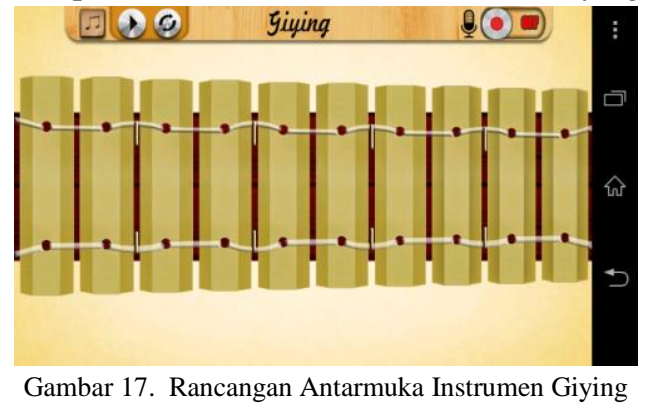

e. Implementasi Antarmuka Instrumen Kendang Gupekan Lanang 


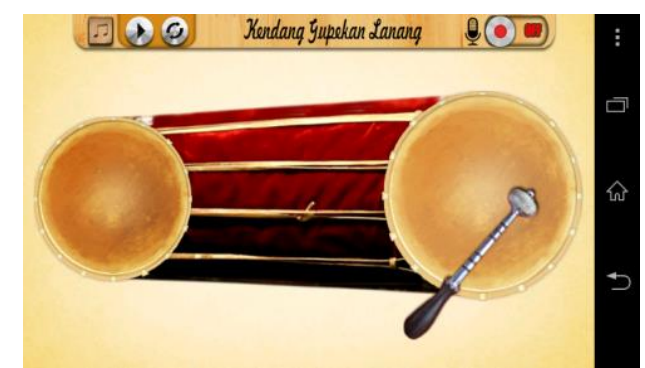

Gambar 18. Rancangan Antarmuka Instrumen Kendang Gupekan Lanang

f. Implementasi Antarmuka Instrumen Cengceng Gecek

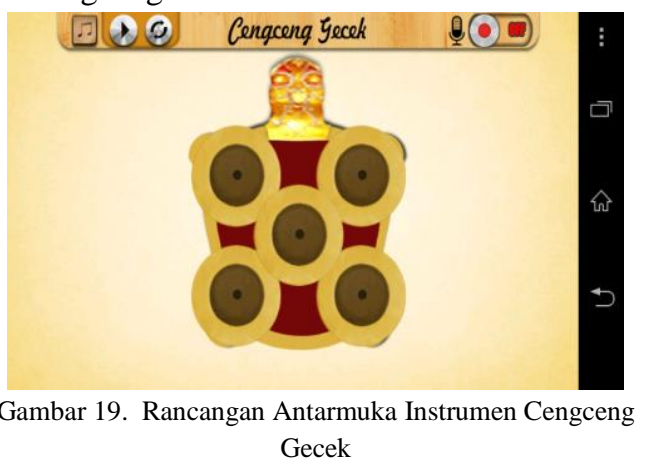

g. Implementasi Antarmuka Download

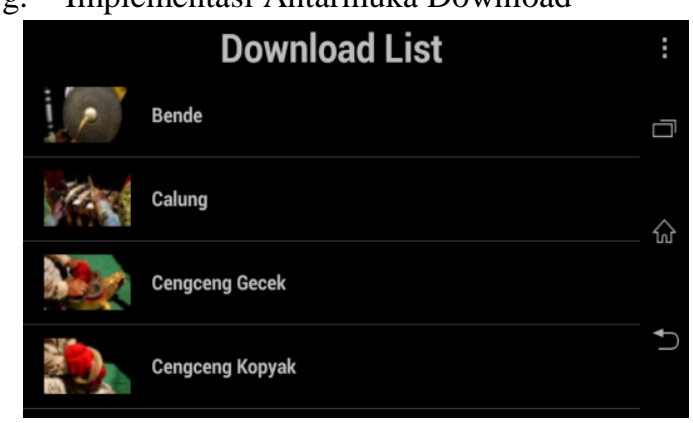

Gambar 20. Rancangan Antarmuka Download

\section{h. Implementasi Antarmuka Video}

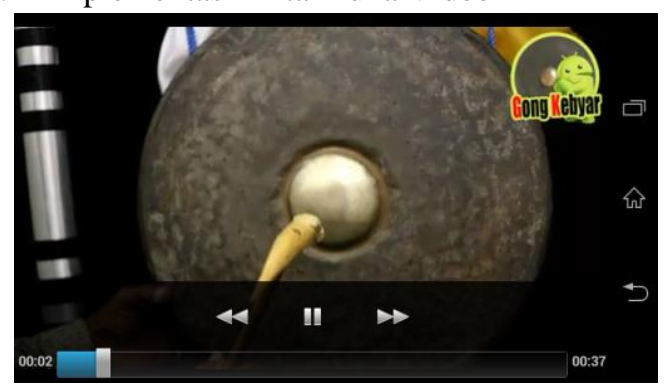

Gambar 21. Rancangan Antarmuka Daftar Video

i. Implementasi Antarmuka Daftar Rekaman

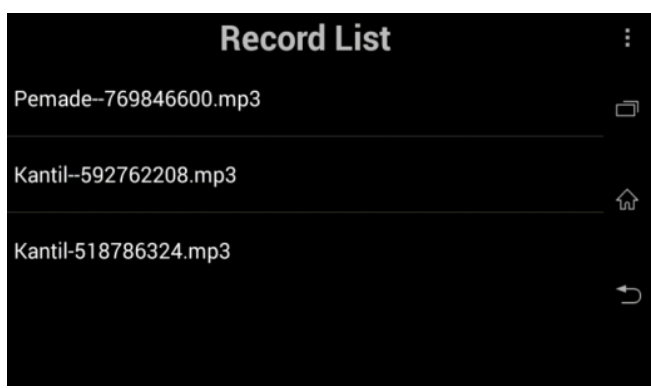

Gambar 22. Rancangan Antarmuka Daftar Rekaman

B. Pengujian Perangkat Lunak

1. Tujuan Pengujian Perangkat Lunak

Tujuan pengujian aplikasi Aplikasi Instrumen Gamelan Gong Kebyar berbasis Android, yaitu:

a. Menguji penggunaan aplikasi instrumen gamelan Gong Kebyar berbasis Android pada perangkat Android yang berbeda.

b. Menguji kebenaran proses aplikasi instrumen gamelan Gong Kebyar berbasis Android.

c. Menguji kualitas suara dan musik yang dihasilkan aplikasi dengan speaker perangkat Android .

d. Menguji kualitas suara dan musik yang dihasilkan aplikasi dengan speakerlearphone tambahan.

e. Menguji kualitas suara yang dihasilkan aplikasi jika instrumen dimainkan oleh 4 orang atau lebih secara bersama-sama dengan menggunakan speaker tambahan.

f. Menguji waktu respon dari suara instrumen saat aplikasi dimainkan oleh 4 orang atau lebih secara bersama-sama dengan menggunakan speaker tambahan.

2. Perancangan Kasus Uji Pengujian Perangkat Lunak

Pada tahap ini dideskripsikan secara mendetail bentuk bentuk uji kasus yang akan dilaksanakan sesuai dengan tujuan pengujian dan tata ancang pengujian yang telah ditetapkan. Uji kasus yang dibuat selengkap mungkin agar hasil pengujian lebih valid. Terdapat enam kasus uji yang dirancang sesuai dengan tujuan pengujian perangkat lunak yang digambarkan dengan angket pengujian.

3. Pelaksanaan Pengujian Perangkat Lunak 
Pelaksanaan pengujian aplikasi Instrumen Gamelan Gong Kebyar Berbasis Android dilakukan pada 10 perangkat Android dengan spesifikasi yang bervariasi. Pengujian pada 10 perangkat yang berbeda bertujuan untuk mengetahui performa dan kompabilitas dari masing-masing perangkat dalam menjalankan aplikasi Instrumen Gamelan Gong Kebyar Berbasis Android.

Pengujian dilakukan sesuai dengan tata ancang dan teknik pengujian perangkat lunak dengan menggunakan angket yang telah dirancang dan pengamatan langsung. Pengujian dilaksanakan pada tanggal 27 dan 29 April 2014, 11 dan 16 Mei 2014, 16 dan 29 Juni 2014 dengan penguji yaitu mahasiswa Jurusan Pendidikan Teknik Informatika berjumlah 10 orang, rekan-rekan dari UKM (Unit Kegiatan Mahasiswa) Kesenian Daerah Universitas Pendidikan Ganesha yang berjumlah 7 orang, dan seorang penguruk tabuh yaitu I Ketut Sudiasa.

\section{Evaluasi Hasil Pengujian Perangkat Lunak}

Berdasarkan pengujian yang telah dilakukan, aplikasi instrumen gamelan Gong Kebyar berbasis Android dapat dijalankan pada semua perangkat Android yang diujikan sesuai dengan kebutuhan minimum aplikasi yang telah ditetapkan. Pengujian dilakukan dengan menggunakan beberapa merk perangkat Android diantaranya Sony, Samsung, Ainol, Lenovo, Polytron dengan spesifikasi yang bervariasi. Seluruh fitur yang terdapat pada aplikasi instrumen gamelan Gong Kebyar berbasis Android dapat dijalankan pada semua perangkat yang diujikan dan tidak terjadi error. Kualitas suara dan musik dari aplikasi akan lebih baik jika menggunakan speakerlearphone tambahan khsusunya untuk suara instrumen Gong, Kempur, dan Jegogan. Pengujian kualitas suara dan waktu respon yang dilakukan oleh 4 dan 7 orang secara bersama-sama dengan tabuh Gegilak menghasilkan suara yang baik. Suara yang dihasilkan dari instrumen pada aplikasi mampu memberikan alunan gamelan yang harmonis.

\section{SIMPULAN}

Berdasarkan penelitian dan pengembangan aplikasi instrumen gamelan Gong Kebyar berbasis Android yang telah dilakukan, maka diperoleh kesimpulan sebagai berikut.

1. Aplikasi instrumen gamelan Gong Kebyar berbasis Android merupakan aplikasi yang memvirtualkan instrumen gamelan Gong Kebyar agar bisa digunakan pada perangkat yang menggunakan sistem operasi Android.

2. Perancangan Aplikasi instrumen gamelan Gong Kebyar berbasis Android telah berhasil dilakukan dengan menggunakan model fungsional berupa UML (Unified Modeling Languange) yaitu dengan menggunakan use case diagram, activity diagram, dan sequence diagram.

3. Aplikasi instrumen gamelan Gong Kebyar berbasis Android telah berhasil diimplementasikasan sesuai dengan rancangan yang telah dibuat sebelumnya. Aplikasi instrumen gamelan Gong Kebyar berbasis Android diimplementasikan menggunkan bahasa pemrograman Java dengan editor Eclipse versi 4.2.1 dan plug-ins ADT (Android Development Tools) serta menggunakan AndEngine sebagai library tambahan.

4. Aplikasi Instrumen Gamelan Gong Kebyar berbasis Android mampu diinstal dan dioperasikan pada 10 perangkat Android yang berbeda-beda pada uji coba.

5. Aplikasi Instrumen Gamelan Gong Kebyar berbasis Android mampu dimainkan secara multi pengguna.

Saran untuk pengembangan aplikasi selanjutnya adalah agar ditambahkan hal-hal seperti berikut.

1. Menambahkan beberapa instrumen gamelan Gong Kebyar pada barungan ageng ke dalam aplikasi.

2. Membuat aplikasi lebih ringan agar respon time dari pengguna cepat dieksekusi program.

3. Membuat suatu perangkat keras agar pemain bisa bermain secara bersama-sama pada.

4. Aplikasi mampu menentukan keras atau lemahnya suara instrumen dari sentuhan pengguna pada perangkat.

5. Aplikasi mampu dikembangkan pada sistem operasi mobile lainnya.

6. Aplikasi memiliki fitur seperti komposer. 
ISSN 2087-2658

Jurnal Nasional Pendidikan Teknik Informatika (JANAPATI)

Volume 4, Nomor 2, Juli 2015

\section{REFERENSI}

[1]. Widyosismoyo, Supartono. 2004. "Ilmu Budaya Dasar. Bogor": Ghalia Indonesia.

[2]. Linggih, I Nyoman. 2010. "Patung Dewa Ruci Dalam Perspektif Budaya Bali". Terdapat pada http://www.isidps.ac.id/berita/

patung-dewa-ruci-dalam-perspektif-budaya-bali. (Diakses pada tanggal 15 Desember 2013).

[3]. Suharta, I Wayan dan Yulianti, Ni Ketut Dewi. 2011 "Signifikansi Bahasa Inggris dalam Proses BelajarMengajar Gamelan Gong Kebyar bagi Mahasiswa Asing dalam upaya ISI Denpasar Go Internasional". Terdapat pada http://repo.isi-dps.ac.id/ 755/1/Signifikansi_Bahasa_Inggris_Dalam_Proses_Belaj ar-Mengajar_Gamelan_Gong_Ke byar_Bagi_Mahasiswa_Asing_Dalam_Upaya_ISI_Denpa sar_Go_International.pdf. (Diakses tanggal 5 Desember 2013).

[4]. Mubah, Safril. 2011. "Strategi Meningkatkan Daya Tahan Budaya Lokal dalam Menghadapi Arus Globalisasi”. Masyarakat, Kebudayaan dan Politik. Terdapat pada http://journal.unair.ac.id/filerPDF/03\%20Safril\%20Strate gi\%20Meningkatkan\%20Daya\%20Tahan\%20Budaya\%2 0Lokal\%20Safril\%20mda.pdf. (Diakses pada tanggal 8 April 2014).

[5]. Joewono, Benny N (Ed). 2012.” Prof Rai: Gamelan Bali Berkembang di Mancanegara". Terdapat pada http://regional.kompas.com

/read/2012/03/14/0716209/Prof.Rai.Gamelan.Bali.Berke mbang.di.Manca.Negara. (Diakses tanggal 15 Desember 2013).

[6]. Triadi, Dendy. 2013. "Bedah Tuntas Fitur Android". Yogyakarta : Great Publisher.

[7]. Suprianto, Dodit dan Agustina, Rini. 2012. "Pemrograman Aplikasi Android". Cetakan Pertama. Jakarta: MediaKom.

[8]. Wismono, Andi Taru Nugroho. 2012. "Cara Mudah Membuat Game di Android". Yogyakarta : ANDI.

[9]. Dharwiyanti, Sri dan Wahono, Romi Satria. 2003. "Pengantar Unified Modeling Language (UML)". Terdapat pada http://setia.staff.gunadarma.ac.id/Downloads/files/6039/ MateriSuplemenUml.pdf. (Diakses tanggal 8 April 2014). 